\title{
Generalizing Ecological Effects of Shoreline Armoring Across Soft Sediment Environments
}

\author{
J. E. Dugan ${ }^{1}$ - K. A. Emery ${ }^{1,2} \cdot$ M. Alber ${ }^{3}$ - C. R. Alexander ${ }^{4}$ - J. E. Byers ${ }^{5}$. \\ A. M. Gehman ${ }^{5}$ - N. McLenaghan ${ }^{3}$ - S. E. Sojka ${ }^{6}$
}

Received: 25 October 2016 / Revised: 9 April 2017 / Accepted: 13 April 2017 /Published online: 24 July 2017

(C) The Author(s) 2017, corrected publication 2019

\begin{abstract}
Despite its widespread use, the ecological effects of shoreline armoring are poorly synthesized and difficult to generalize across soft sediment environments and structure types. We developed a conceptual model that scales predicted ecological effects of shore-parallel armoring based on two axes: engineering purpose of structure (reduce/slow velocities or prevent/ stop flow of waves and currents) and hydrodynamic energy (e.g., tides, currents, waves) of soft sediment environments. We predicted greater ecological impacts for structures intended to stop as opposed to slow water flow and with increasing hydrodynamic energy of the environment. We evaluated our predictions with a literature review of effects of shoreline armoring for six possible ecological responses (habitat distribution, species assemblages, trophic structure, nutrient cycling, productivity, and connectivity). The majority of studies were in low-
\end{abstract}

Communicated by Marianne Holmer

Electronic supplementary material The online version of this article (doi:10.1007/s12237-017-0254-x) contains supplementary material, which is available to authorized users.

J. E. Dugan

j_dugan@lifesci.ucsb.edu

1 Marine Science Institute, University of California, Santa Barbara, CA, USA

2 Department of Environmental Sciences, University of Virginia, Charlottesville, VA, USA

3 Department of Marine Sciences, University of Georgia, Athens, GA, USA

4 Skidaway Institute of Oceanography, University of Georgia, Savannah, GA, USA

5 Odum School of Ecology, University of Georgia, Athens, GA, USA

6 Randolph College, Lynchburg, VA, USA energy environments (51 of 88), and a preponderance addressed changes in two ecological responses associated with armoring: habitat distribution and species assemblages. Across the 207 armoring effects studied, $71 \%$ were significantly negative, $22 \%$ were significantly positive, and $7 \%$ reported no significant difference. Ecological responses varied with engineering purpose of structures, with a higher frequency of negative responses for structures designed to stop water flow within a given hydrodynamic energy level. Comparisons across the hydrodynamic energy axis were less clear-cut, but negative responses prevailed $(>78 \%)$ in high-energy environments. These results suggest that generalizations of ecological responses to armoring across a range of environmental contexts are possible and that the proposed conceptual model is useful for generating predictions of the direction and relative ecological impacts of shoreline armoring in soft sediment ecosystems.

Keywords Coastal armoring · Shore protection structures . Salt marsh $\cdot$ Mangrove $\cdot$ Estuary $\cdot$ Beach $\cdot$ Ecosystem function

\section{Introduction}

Soft sedimentary shores composed of mud, sand, and gravel make up the majority (two thirds) of the world's coastlines (Reise 2001). Soft sediments are associated with a variety of ecosystems including beaches, dunes, coastal bluffs, marshes, estuaries, bays, and inlets (Nordstrom 2000). These areas provide a range of ecosystem functions and services, ranging from storm protection to wildlife habitat to carbon sequestration (e.g., Snelgrove 1999; Piersma 2009). Human use of the shore is intense, with most of the world's megacities and more than 600 million people living in the coastal zone (Neumann et al. 2015). The coasts are the sites of major cities, ports, and residential development, and many areas have been altered to 
accommodate human activities such as agriculture and commerce.

Soft sedimentary shores are inherently dynamic, and this has led to the installation of coastal armoring structures built for the purpose of protecting upland areas and slowing or halting erosion and migration of the shoreline (Nordstrom 2000; Rippon 2001; Charlier et al 2005; Griggs2005a, b). Shoreline armoring is widely used on all types of open and sheltered coasts and is being increasingly applied to soft sediment shores to protect human infrastructure and reduce shoreline retreat (Bulleri and Chapman 2010; Gittman et al. 2015). The resulting proliferation of shoreline armoring in the second half of the twentieth century has led to extensive hardening of coastlines in many regions (Nordstrom 2000; Airoldi et al. 2005). Thousands of kilometers of armoring are present on the coasts of Europe and Japan, and up to $60 \%$ of the shoreline has been armored along some urban coasts (Airoldi et al. 2005). In the USA, armoring is also widespread, occupying $12-30 \%$ of the total shorelines of individual states and reaching proportions of 50-70\% or more along urban coasts (Gittman et al. 2015). Furthermore, the extent of armoring is expected to increase as a result of expanding coastal populations and cities interacting with growing threats from climate change, storm surges, and sea level rise.

Armoring of shorelines results in a suite of geomorphic and physical effects on soft sediment coastal ecosystems (e.g., Nordstrom 2014). By fixing shoreline position, armoring constrains possible responses and evolution of soft shores to changes in sea level and other dynamic coastal processes (Griggs 2010). The most immediate effect of an armoring structure is placement loss, which is the direct loss of shoreline habitat resulting from the footprint of the structure itself (e.g., Kraus and McDougal 1996). Placement loss can be substantial in high-energy environments where larger dimensions are necessary to ensure that the armoring structure is stable. The presence of armoring along a coast also alters hydrodynamics, modifying the flow of water and affecting sediment dynamics of soft shore environments (e.g., Fletcher et al. 1997; Miles et al. 2001; Runyan and Griggs 2003; Martin et al. 2005). The hardened faces of alongshore structures, such as seawalls and revetments placed on beaches, reflect wave energy and constrain natural landward migration of the shoreline, generally leading to the loss of beach area and width as well as flanking erosion of adjacent shorelines (e.g., Hall and Pilkey 1991; Griggs 2005a, b, 2010). The geomorphic and erosive processes involved in these shoreline changes have been well described through numerical, laboratory, and field studies (e.g.,Kraus and McDougal 1996; Ruggiero 2010), and coastal engineers have a fairly good understanding of which aspects of the physical environment must be considered when installing shoreline armoring in different coastal settings. For example, the US Army Corps of Engineers has developed guidance that can be used to calculate stable sizes for armoring structures intended for different shorelines (USACE 2002, Coastal Engineering Manual).

In contrast, the ecological responses to shoreline armoring have received far less attention and are difficult to generalize across ecosystems and structure types. Although recent reviews on ecological responses to armoring are valuable and are beginning to address this important gap (e.g., Bulleri and Chapman 2010; Dugan et al. 2012; Nordstrom 2014; Perkins et al. 2015; Gittman et al. 2016b), the majority of available studies have been conducted in a specific ecosystem, precluding a critically needed broader synthesis across soft sediment ecosystems. For example, there is evidence that the presence of armoring affects water quality (i.e., Bolduc and Afton 2004), habitat connectivity (i.e., Dugan and Hubbard 2006), and species distributions (i.e., Morley et al. 2012). However, these studies were conducted in a tidal marsh, an open coast beach, and an estuarine beach, respectively, so they cannot be evaluated across a common framework. Moreover, one would expect that ecological responses to armoring would vary depending on the type of structure installed (e.g., seawalls vs. breakwaters vs. constructed oyster reefs) and its relative location on the shore profile. In other words, the ecological effects of armoring are expected to be context dependent based on both the characteristics of the environment and those of the armoring structure itself.

To address the need for a common synthetic framework on ecological effects of armoring, we developed and evaluated a conceptual model that allows more general comparisons of ecological responses of soft sediment coastal ecosystems to armoring across the spectrum of open to sheltered shores and a range of different types of armoring structures. We predicted that ecological effects would intensify as (1) a function of increasing energy at the armoring structure and (2) with increasing influence of the structure in modifying the velocities and flow of water from waves and currents. These formed the two axes of our conceptual model. To critically evaluate the predictive power of our conceptual model, we identified a suite of six general categories of ecological responses that we expected would be affected by the presence of armoring. We then conducted a literature review of studies on the ecological effects of a diversity of shore-parallel armoring structures ranging from living shorelines to seawalls across a spectrum of soft sediment environments. We categorized our literature review results according to the hydrodynamic energy of the environment and the intended effects of each armoring structure on water velocities and flow. We quantified the number and direction of significant ecological responses reported, which enabled us to assess the predictive power of our conceptual model. We also used our results to identify key data gaps and develop further hypotheses. 


\section{Conceptual Model}

Our analysis focused on shore-parallel structures placed in either the intertidal or the nearshore subtidal zones of the coast. We included numerous types of shoreline armoring and coastal defense structures, such as seawalls, revetments, bulkheads, and breakwaters, as well as sills, constructed oyster reefs, and living shorelines. Living shorelines are highly variable in structure and purpose and sometimes incorporate sills, revetments, plantings, and oyster reefs (see Gittman et al. 2016a). In some manifestations, living shorelines can be indistinguishable from traditional armoring (Pilkey et al. 2012). For our analysis, as long as they were parallel to shore, living shoreline studies were included, regardless of the range of ways in which they were designed and constructed. Although also widespread in a variety of soft sediment environments, our analysis excluded studies of groins, jetties, and other armoring structures built perpendicular to shore.

In order to place this wide variety of armoring structures into a common framework, we asked two key questions: (1) Is the engineering purpose of the structure to slow the velocity of water flow from waves and tides impinging on a shoreline or to completely prevent or stop the flow of water to the shoreline? (2) What is the hydrodynamic energy at the structure? We reasoned that if the purpose of the structure is to stop water flow and the hydrodynamic energy is high, that would require a very different type of armoring and cause more pronounced ecological effects than if the purpose was to slow water flow in a low-hydrodynamic energy setting. Our conceptual model is therefore organized along the axes of the intended effect of the structure on water flow and the hydrodynamic energy at the structure, which allows us to broadly categorize armoring structures as they are applied to different shoreline situations, elevations, and soft sediment environments.

The axis of water flow in the conceptual model can be thought of as a measure of the extent to which water generated by waves and tides is prevented from moving through or over the structure to the shoreline. Impermeable structures generally stop or prevent water flow through or over the structure whereas permeable or low height structures serve to slow water velocity and allow flow through or over the structure to reach the shoreline (Fig. 1, top). The size of the structure is also a consideration, as taller and longer structures will be more effective at stopping water flow to the shoreline. At one end of the spectrum, a seawall or revetment installed to prevent wave and storm surge intrusion is intended to stop water from reaching upland areas. In more sheltered areas, such as harbors and estuaries, a much smaller bulkhead can often provide a similar function. Revetments placed on open coasts designed to stop waves from reaching coastal cliffs, highways, or buildings tend to be tall and wide but are generally considered less reflective of wave energy than a seawall in the same setting. Smaller revetments that are more typical of

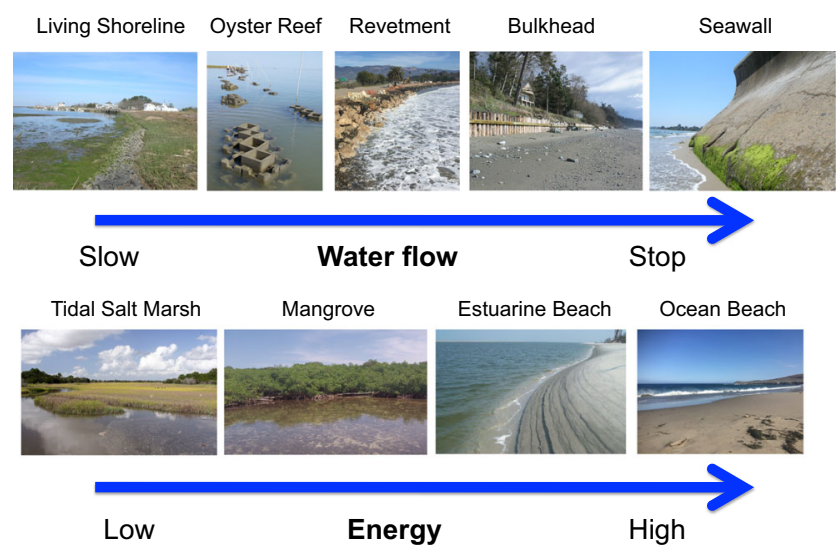

Fig. 1 Illustration of gradients in the two axes of influence for the conceptual model of shoreline armoring effects. Top row Engineering purpose with respect to intended effect of structure on water flow (slow vs. stop). Bottom row Hydrodynamic energy (low to high) at the structure as determined by the environment

sheltered shorelines, however, can often be somewhat more permeable and also tend to be less reflective of hydrodynamic energy than a bulkhead. Shorter structures, such as sills, are generally designed to retain sediments and still allow water to flow across or through the structure, serving to reduce water flow and velocity (Gittman et al. 2014). Again, living shorelines can span a broad range of permeability, size, and purpose with regard to their intended effects on water flow (i.e., Bilkovic et al. 2016; Gittman et al. 2016a).

A second important consideration that determines the type of armoring structure installed in a particular area is the amount of hydrodynamic energy that reaches and interacts with the structure. Hydrodynamic energy, broadly defined, encapsulates several important contributing aspects that affect armoring structure decisions, including the relative influence of waves and tides in the environment and the tidal elevation of the structure. In general, marshes and mangroves are lowerenergy environments with tides dominating the hydrodynamic conditions (tide range/wave height > 3) (Hayes 1979), whereas open coast beaches are high-energy, wave-dominated environments (tide range/wave height $=0.5$ to 1 ) that occupy the opposite end of the hydrodynamic energy spectrum (Fig. 1, bottom). In the middle are medium- or mixed-energy shores influenced by both tides and waves (tide range/wave height $=1$ to 3). Hydrodynamic energy also varies within an environment, based on factors such as the tidal height in the profile at which the structure is placed and the role of local influences such as boat wakes and fetch. For example, the average hydrodynamic energy at a seawall placed well above mean high water on an open coast beach will be lower than that of a seawall located below mean sea level on the same shore profile (e.g., Weggel 1988). Although the conceptual model could theoretically be applied within a single soft sediment habitat (e.g., low vs. high elevation on an estuarine beach), in this study we focused on differences in hydrodynamic energy 
across environments so that we could encompass a broad range of ecosystem types (from beaches to marshes) in our evaluation of the conceptual model.

For our analyses, we used the two axes (effects on water flow and hydrodynamic energy setting) to divide our conceptual model into two categories of intended effects of the structure on water flow to the shoreline (slow or stop water flow) and three levels of hydrodynamic energy of the environment (low, medium, and high). The resulting six boxes (Fig. 2, labeled 1-3 for the hydrodynamic energy level and a or $b$ for the engineering purpose of slowing or stopping water flow) allowed us to scale the effects of shore-parallel armoring structures across a range of soft sediment environments and structure types. One result of this categorization is that the range of possible combinations of coastal armoring structure and ecosystem is bounded, with some types of structures tending to occur more prevalently in certain ecosystems. For example,

\section{Conceptual Model}

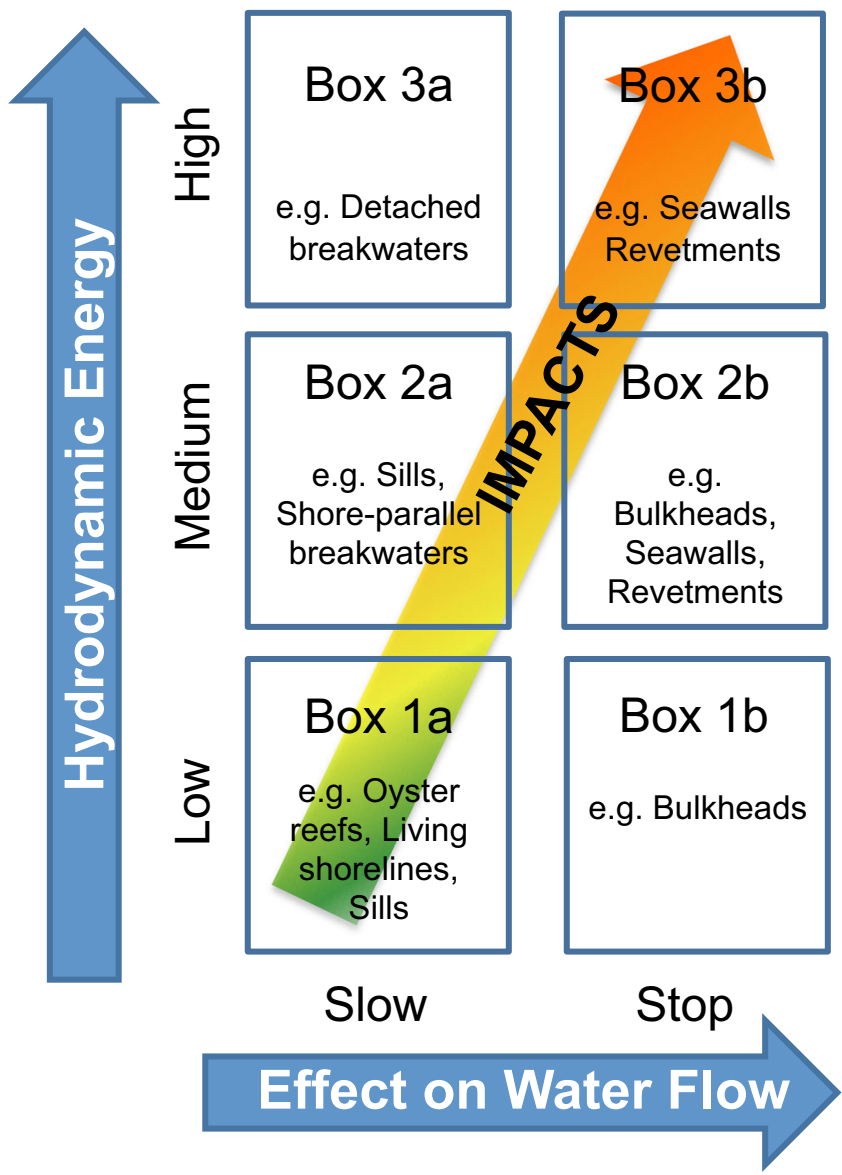

Fig. 2 Conceptual model showing predicted ecological impacts in soft sediment environments across the array of shoreline armoring types used to either slow or stop water flow ( $x$-axis) and with different hydrodynamic energy levels at the armoring structure (y-axis). Ecological impacts are predicted to increase as one moves $u p$ and to the right within the parameter space salt marshes are low in energy, and structures placed there to stop water flow, such as bulkheads (box 1b), are generally lower in height and require a smaller cross-shore footprint to maintain structural stability than in an open coast environment (e.g., USACE 2002). Large, detached breakwaters that slow water flow are found along open coasts (box 3a) or in bays (box 2a) whereas smaller sills are more prevalent in marsh and estuarine settings (box 1a). Revetments that stop or prevent water flow to the shoreline, albeit with less direct reflection of energy than seawalls or bulkheads, can be found on open coast beaches (box 3b) as well as lining the shores of estuaries, harbors, and bays (box 2b).

We used the conceptual model to predict the relative ecological impact of armoring structures given different combinations along the two axes (diagonal arrow in Fig. 2). Along the water flow axis, we predict that structures designed to slow rather than stop water flow will also allow more natural functioning and connectivity of aquatic and terrestrial habitats as opposed to those designed to stop water flow to the shoreline. Modeling studies have demonstrated that increased permeability of armoring structures could reduce wave reflection (e.g., Mallayachari and Sundar 1994; Zhu and Chwang 2001; Karim et al. 2009) and overtopping (e.g., Hieu and Vinh 2012), both of which could decrease sediment erosion and alter hydrology, affecting nutrient cycling and water quality. Impermeable barriers that completely prevent water flow to reach the shoreline will reflect more of the energy from waves and tides than those designed to slow velocity but still allow water flow through the structure to the shoreline. The hydrodynamic energy of the environment (the vertical axis) will also affect the design and impact of the armoring structure both across and within soft sediment environment types. Armoring structures in high-energy shoreline environments tend to be larger than those in low-energy environments (USACE 2002), leading to greater placement loss and, therefore, likely greater impacts to habitat and species distributions. Thus, a structure designed to slow water flow in an environment with low hydrodynamic energy (e.g., a low crested riprap sill in a marsh) would be expected to show the least amount of ecological impact, whereas one designed to stop water flow in a high-energy environment (e.g., a seawall on an open coast beach) would be expected to show the greatest impact. We did not have an a priori expectation as to which of these axes would be more important and so predicted a general upward increase in ecological impacts commensurate with intensification of both factors (Fig. 2).

To investigate these predictions for ecological impacts, we identified six categories of ecological responses that we expected could be altered by the presence of shoreline armoring in soft sediment ecosystems (see Fig. 3 for examples of negative responses). These categories are described below, along with the rationale for each category. 
Fig. 3 Comparison between unarmored (a) and armored (b) shorelines, with examples of effects for the six ecological responses evaluated in this review (E1 habitat distribution, E2 species assemblage, E3 trophic structure, E4 nutrient cycling, E5 productivity, E6 connectivity). Broken ellipses in panel b signify negative impacts and correspond to the ellipse of the same color in panel a

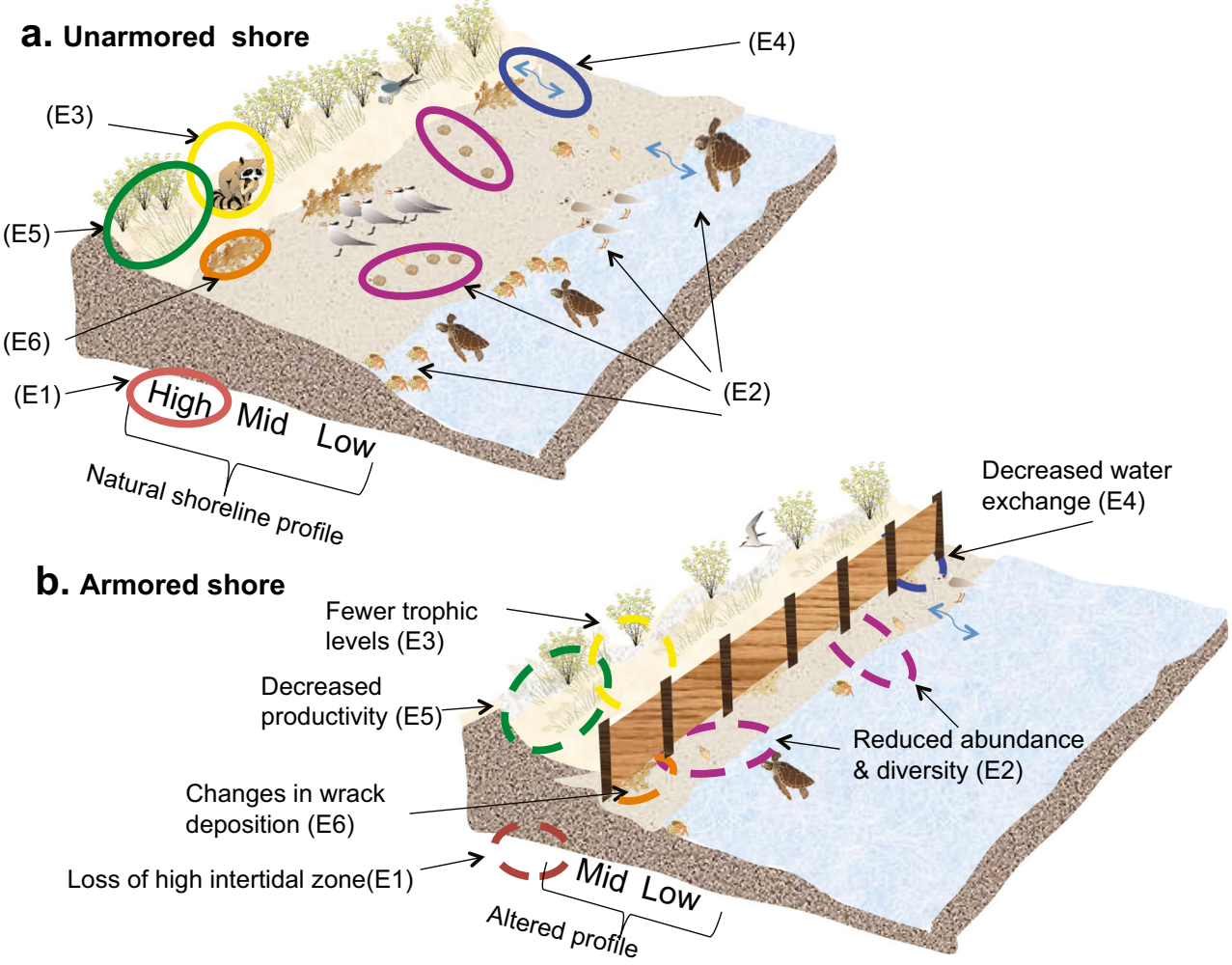

(E1) Habitat Distribution: The loss or alteration of coastal habitats associated with armoring can directly impact many functions of soft sediment ecosystems including species distributions, biodiversity, connectivity, productivity, food webs, and wildlife support. In addition to the immediate placement loss that occurs when the footprint of an armoring structure covers a portion of the shore habitat, over time, the presence of a structure can result in the loss and alteration of intertidal habitat on its seaward side due to increased erosion and subsequent conversion to subtidal habitat (Fig. 3). This can result in a loss of habitat for intertidal biota and of nesting habitat for birds, fish, and sea turtles. Armoring structures can also result in the alteration of habitat characteristics, such as grain size, shore profile, and light regime, which can affect species distributions. By blocking seawater inundation and water flow, armoring can also result in the loss of intertidal habitat on the landward side of a structure and its conversion to upland. Armoring may also provide a novel hard substratum habitat in an area otherwise devoid of anything but soft sediment, and in some cases, this novel habitat may also include three-dimensional aspects, such as the nooks and crannies associated with rock revetments, that increase habitat complexity and provide refuges and microhabitat for some organisms.

(E2) Species Assemblage: The shifts in habitat noted above and other environmental characteristics of armoring structures can affect species assemblages, with consequent implications for biodiversity, abundance, size structure, and community composition (Fig. 3). Armoring structures can also potentially support both native and invasive species that require hard substrates and may provide stepping stones for their dispersal and spread to new areas.

(E3) Trophic Structure: Shifts in trophic and food web structure associated with armoring follow from shifts in habitat characteristics, species distribution, and productivity (Fig. 3). This can include changes in prey or predator abundance, shifts in diet, and altered complexity and functional redundancy of food webs. This category includes effects on animals that forage in coastal soft sediment ecosystems, including birds, fishes, reptiles, and mammals.

(E4) Nutrient Cycling: Changes in hydrology and sediment characteristics associated with armoring will likely affect microbial communities and biogeochemical cycling with impacts to nutrient cycling, rates (i.e., denitrification), organic matter dynamics, and oxygen levels (Fig. 3). The presence of the structure may also interfere with water exchange across the interface, potentially reducing surface water runoff and associated nutrients from the upland.

(E5) Productivity: Primary production may be affected by the presence of armoring, particularly if there are changes in light (through shading) or nutrient availability (Fig. 3). Primary production includes that of 
phytoplankton, macroalgae, vascular plants, and microphytobenthos. Secondary production may be affected as well, either as a consequence of changes in primary production or changes in habitat and species distribution.

(E6) Connectivity: Armoring can represent a physical barrier that interferes with the exchange and accumulation of organisms, wrack, litter, sediment, and propagules on the shoreline (Fig. 3). Depending on the location of the structure, this can prevent or deter the movement between upland, intertidal, and subtidal areas and affect vital shoreline ecotones at the boundary of land and sea. Loss of connectivity has implications for many of the other ecological effects described above, such as nutrient cycling, productivity, species assemblages, and trophic structure.

\section{Methods: Literature Review and Evaluation of Conceptual Model}

To evaluate the predictions of our conceptual model, we used the results of a literature review that focused on the six categories of ecological responses to shoreline armoring (E1-E6) we identified. We conducted a systematic search of Google Scholar and Web of Science using key words related to armoring (breakwater, bulkhead, coastal armoring, coastal hardening, living shoreline, oyster reef, riprap, revetment, seawall, shoreline armoring, shoreline hardening, sill, impoundment) and environment (beach, estuary, lagoon, mangrove, salt marsh, tidal creek, harbor, river mouth). This was augmented by papers that came to our attention through conferences and other means as we were conducting this effort. Papers were included in the literature review if they contained ecological results.

We classified each study in terms of environment and type of armoring structure to assign it into one of the six boxes in our conceptual model. Due to the limited scope of information available, we did not further classify studies or study results based on tidal elevation, size (height and length), submergence regime, or construction material of the armoring structures for our analysis.

We identified which of the six categories of ecological responses were evaluated in each study and whether the effects were significantly positive, significantly negative, or not significant according to the authors of each paper reviewed. Examples of negative responses are illustrated in Fig. 3, and additional examples of positive and negative responses are provided in Table S1.

In studies where more than one box in the conceptual model was studied or more than one ecological response category was evaluated, we assessed each box and/or response category result separately. However, if more than one variable was measured within a particular effect category, it was only counted once. For example, if a study measured the abundance of multiple species, it was only included once under species assemblage (E2). In most cases, multiple variables responded similarly (i.e., there were significant reductions in all species evaluated). In the few cases where there were mixed results, a paper was scored according to the majority of effects (i.e., if the abundance of four out of five species was significantly reduced, this was counted as a negative effect). Effects of armoring on habitat distribution (E1) and species assemblages (E2) were often reported together (i.e., a change in habitat was associated with a change in species distribution or abundance). We separated these effects for our analyses by assigning changes in habitat availability or quality, including nesting habitat, to E1 and changes in abundance or distribution of organisms to E2.

\section{Results}

We located a total of 88 studies that evaluated ecological effects of shore-parallel coastal armoring on soft sediment environments (Table S2). The majority of studies $(n=51)$ were conducted in low-energy environments: most of these were conducted in salt marshes and tidal creeks $(n=47)$ and only four in mangroves. A total of 24 studies were conducted in medium-energy systems, including studies in harbors, river mouths, and estuaries. We located only 13 ecological studies conducted in high-energy environments, the majority of which were conducted on open coast sandy beaches.

The majority of studies in low-energy environments investigated structures designed to slow water (Box 1a), such as sills, rather than stop water flow (e.g., bulkheads) (Box 1b) (Fig. 2, Table 1). Box 1a in our conceptual model included most of the living shoreline and oyster reef studies but also

Table 1 Distribution of studies of ecological effects of shoreline armoring across the axes of hydrodynamic energy and intended effect of armoring structure on water flow that define the six boxes in the conceptual model

\begin{tabular}{lll}
\hline Hydrodynamic energy of environment & \multicolumn{2}{l}{ Effect on water flow } \\
\cline { 2 - 3 } & $\begin{array}{l}\text { Slow } \\
\text { a }\end{array}$ & $\begin{array}{l}\text { Stop } \\
\text { b }\end{array}$ \\
\hline High: 3 & 5 & 11 \\
Medium: 2 & 13 & 19 \\
Low: 1 & 36 & 24 \\
\hline
\end{tabular}

Note that the total for this table $(n=108)$ exceeds the number of studies (88) because studies that examined more than one structure type were represented in multiple boxes of the conceptual model, as appropriate 
included sill, revetment, and riprap installations in low-energy environments, whereas Box $1 \mathrm{~b}$ primarily included studies of bulkheads and impoundments designed to stop water flow. Studies in the medium-energy environments were split fairly evenly between structures designed to slow vs. stop water (Table 1). Those in Box 2a of the model included studies of detached breakwaters in harbors and bays, whereas those in Box $2 \mathrm{~b}$ included studies of seawalls, bulkheads, and shoreline revetments. For high-energy environments, there were more studies of structures designed to stop water flow (Table 1). Box 3a of our model included studies of detached breakwaters that were mostly conducted along open sandy coastlines while Box $3 \mathrm{~b}$ covered studies of seawalls and massive revetments on open coast sandy beaches.

We identified results that covered all of the six categories of ecological response variables (E1-E6), indicating a surprisingly wide range of investigations of the ecological impacts of armoring (Table 2). However, a preponderance of these was focused on alterations in E2 (species assemblage (94)), followed by E1 (habitat distribution (57)). There were far fewer studies that evaluated the responses to armoring in regard to E3 (trophic structure (18)), E4 (nutrient cycling (18)), E5 (productivity (13)), and E6 (connectivity (7)). Below, we summarize the results for each of the ecological responses and then compile the information into an overview of positive and negative effects across all categories. Mixed results were rare and only reported in three studies. A list of the individual papers included in this analysis along with their assigned boxes, ecological response variables, and significant effects can be found in Table S2.

\section{E1: Habitat Distribution}

The effects of coastal armoring on habitat distributions and availability were well represented in the literature review with a total of 57 observations, with studies measuring effects in terms of intertidal zone widths and distributions, habitat characteristics (e.g., depth, elevation, slope, and grain size), and nursery and nesting habitat for birds, fish, and sea turtles as well as the provision of novel hard substrate habitats for epifauna. The majority of these observations were reported for low-energy environments (33 in salt marsh and tidal creeks and 1 in mangroves), but results were available for mediumenergy environments (14) and high-energy environments (9). Similar numbers of studies evaluated armoring structures placed to slow (30) as opposed to stop (27) water flow for this response (Fig. 4). Of the 57 observations related to effects on habitat associated with armoring, 38 were negative, 17 were positive, and 2 were detected to have no difference.

The large numbers of studies of armoring effects on habitat distribution was spread among all six boxes of our conceptual model (Fig. 4). Where structures were installed to slow water in low-energy environments, Box 1a, a mix of positive and negative responses was reported. Multiple studies concluded that adding constructed oyster reefs, living shorelines, or permeable riprap armoring structures provided significant new habitat area (e.g., Davis et al. 2002. Piazza et al. 2005, Swann 2008, Powers et al. 2009, Scyphers et al. 2014, Gittman et al. 2016a). However, a myriad of negative observations was also reported for Box 1a. Armoring, including riprap and marsh impoundments, eliminated habitat, reduced habitat quality, or provided habitat suitable for invasive species (Hendon et al. 2000; Peterson et al. 2000; Boys et al. 2012; Geraldi et al. 2014; Lowe and Peterson 2014; Patrick et al. 2014, 2016). For Box $1 \mathrm{~b}$ of our model, where bulkheads and seawalls were put in place to stop the flow of water in lowenergy environments, all observations were negative except for one where a bulkhead was reported to provide new habitat for epifaunal communities (Wong et al. 2011). In all other studies of salt marshes and tidal creeks in which the armoring structure was designed to stop water flow (Box 1b), studies reported that habitat was lost, habitat quality was reduced, or

Table 2 Distribution of study results from the literature review that were reported as significantly positive, negative, and not significant (NS) for each of the six ecological responses (E1-E6) in each of the six boxes of our conceptual model (1a, 2a, 3a, 1b, 2b, and 3b)

\begin{tabular}{|c|c|c|c|c|c|c|c|c|c|c|c|c|c|c|c|c|c|c|}
\hline \multirow[t]{2}{*}{ Direction of response } & \multicolumn{3}{|c|}{ Box 1a } & \multicolumn{3}{|c|}{ Box $1 b$} & \multicolumn{3}{|c|}{ Box 2a } & \multicolumn{3}{|c|}{ Box $2 b$} & \multicolumn{3}{|c|}{ Box 3a } & \multicolumn{3}{|c|}{ Box $3 b$} \\
\hline & + & - & NS & + & - & NS & + & - & NS & + & - & NS & + & - & NS & + & - & ND \\
\hline E1: Habitat Distribution & 10 & 8 & 2 & 1 & 13 & 0 & 4 & 3 & 0 & 1 & 6 & 0 & 1 & 2 & 0 & 0 & 6 & 0 \\
\hline E2: Species Assemblage & 12 & 15 & 4 & 1 & 18 & 0 & 3 & 8 & 1 & 2 & 14 & 0 & 1 & 5 & 0 & 0 & 9 & 1 \\
\hline E3: Trophic Structure & 3 & 2 & 1 & 1 & 4 & 0 & 0 & 0 & 0 & 0 & 3 & 1 & 1 & 0 & 0 & 0 & 2 & 0 \\
\hline E4: Nutrient Cycling & 1 & 8 & 1 & 1 & 4 & 0 & 0 & 1 & 0 & 0 & 1 & 1 & 0 & 0 & 0 & 0 & 0 & 0 \\
\hline E5: Productivity & 1 & 5 & 1 & 1 & 2 & 1 & 0 & 0 & 0 & 0 & 0 & 0 & 0 & 0 & 0 & 0 & 2 & 0 \\
\hline E6: Connectivity & 0 & 1 & 0 & 0 & 1 & 0 & 0 & 1 & 0 & 0 & 3 & 0 & 0 & 0 & 0 & 0 & 1 & 0 \\
\hline Total & 27 & 39 & 9 & 5 & 42 & 1 & 7 & 13 & 1 & 3 & 27 & 2 & 3 & 7 & 0 & 0 & 20 & 1 \\
\hline
\end{tabular}

Numerous studies reported multiple ecological effects which resulted in the total sample size $(n=207)$ presented here 


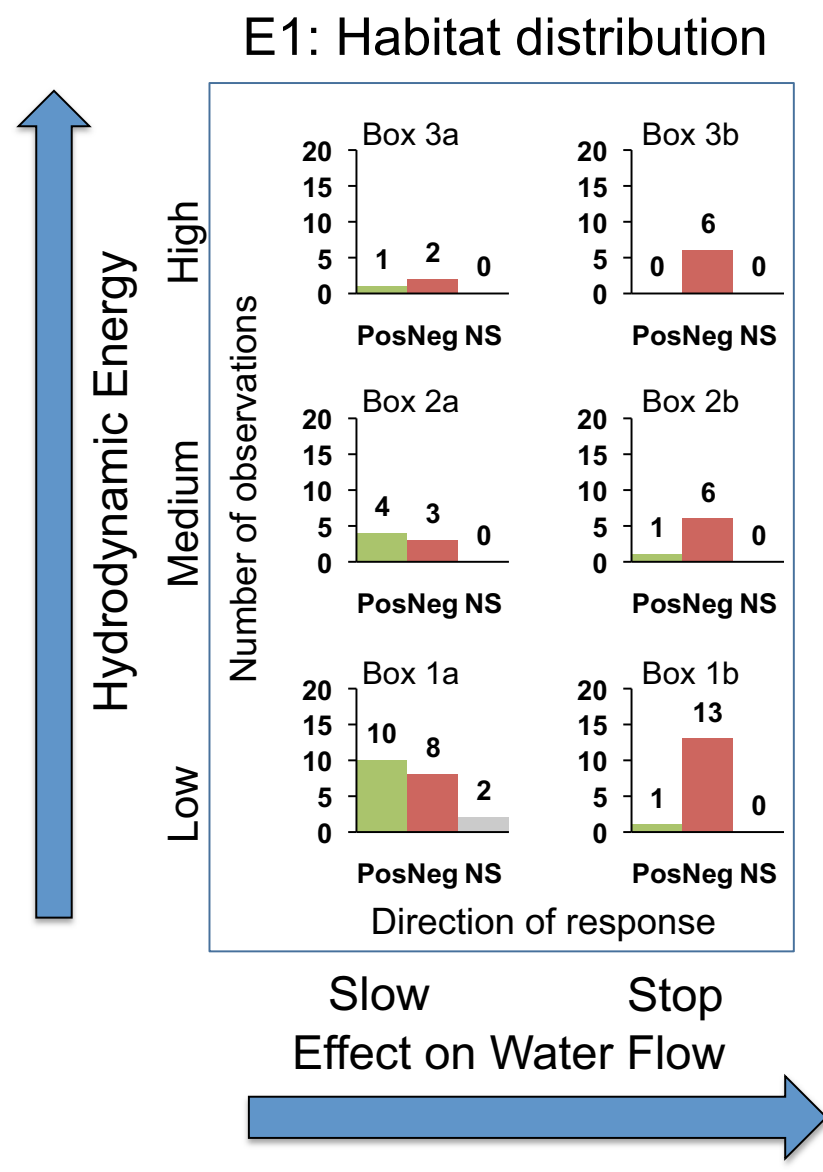

Fig. 4 Ecological effects on habitat distribution (E1) reported in studies included in our literature review. The histograms correspond to the six combinations of intended effects of an armoring structure on water flow and the hydrodynamic energy of the environment represented by the boxes in the conceptual model (Fig. 2). In the histogram for each box, the number of significantly positive (green), negative (red), and not significant (NS) (gray) observations is plotted

the armoring structures provided habitat for undesirable invasive species (e.g., Bozek and Burdick 2005; Baily and Pearson 2007; Freiss et al. 2008; McPherson 2009; Balouskus and Targett 2012; Gittman et al. 2016b). Similarly, seawalls in mangrove ecosystems resulted in reduced mangrove forest habitat area (Heatherington and Bishop 2012).

For Box 2a of our model, where structures were put in place to slow water in medium-energy environments, effects on habitat were again mixed. Permeable structures such as riprap structures, oyster reefs, and constructed habitat benches provided habitat, often by increasing the availability of structurally complex habitat (Toft et al. 2007, 2013; Pister 2009; Drexler et al. 2014). Other studies, however, found that riprap structures eliminated soft sediment intertidal and benthic habitat (Sobocinski et al. 2010; Heerhartz et al. 2014; Dethier et al. 2016). For Box 2b, where seawalls and bulkheads were used to stop water flow, all observations but one were negative. Although Drexler et al. (2014) found that seawalls provided habitat for oysters, many other studies found that these structures generally reduced habitat (Bilkovic and Roggero 2008; Sobocinski et al. 2010; Heerhartz et al. 2014; Dethier et al. 2016) unless remedial actions were undertaken to increase habitat complexity (Browne and Chapman 2011, 2014).

For structures installed to slow water in high-energy environments (Box 3a), Martin et al. (2005) concluded that a lowcrested breakwater structure provided new habitat, but others reported that breakwaters, revetments, and low-crested structures reduced structural complexity and eliminated habitat (Moschella et al. 2005; Vaselli et al. 2008). For Box 3b of our model, several studies found that seawalls reduced or eliminated intertidal and upper shore and coastal dune habitats in sandy beach ecosystems (Dugan and Hubbard 2006; Dugan et al. 2008; Jaramillo et al. 2012; Rodil et al. 2015). Negative results were also reported where armoring reduced the quality of critical beach nesting habitats for sea turtles, a globally threatened group (Rizkalla and Savage 2011).

When taken together, the majority of the results for habitat distribution (72\%) were negative, particularly for structures designed to stop the flow of water ( $92 \%$ overall), a result in agreement with predictions of our conceptual model. These negative results were most commonly associated with the loss of habitat area and reduced habitat quality. For structures intended to slow the flow of water, positive results made up $50 \%$ of the results in Box 1a, $57 \%$ for Box 2a, and 33\% in Box $3 \mathrm{a}$. Most of these were associated with constructed oyster reefs and living shorelines that provided new habitat for native species.

\section{E2: Species Assemblages}

Effects on species assemblages were the most commonly documented ecological response to shoreline armoring in our review, with a total of 94 observations. The majority of these were in low-energy habitats (47 in salt marsh and tidal creek ecosystems, 3 in mangroves), with 25 in medium-energy habitats and only 16 observations in high-energy open coast environments. Approximately equal numbers of studies evaluated structures placed to slow (49) as opposed to stop (45) water flow.

A majority of the significant responses of species assemblages to armoring were considered negative (69), with only 19 reports of positive responses and 6 reports of no significant differences detected (Fig. 5). When distributed across the boxes of our conceptual model, we found that most of the positive responses were observed for Box 1a (structures designed to slow water in low-energy environments). Positive results included increases in epiphyte and epifaunal abundance and diversity on the structures themselves (e.g., Wong et al. 2011; Peters et al. 2015), particularly for oysters (e.g., Piazza et al. 2005; Powers et al. 2009; Scyphers et al. 2011), as well as increases in other invertebrates and in fish on living 


\section{E2: Species assemblage}

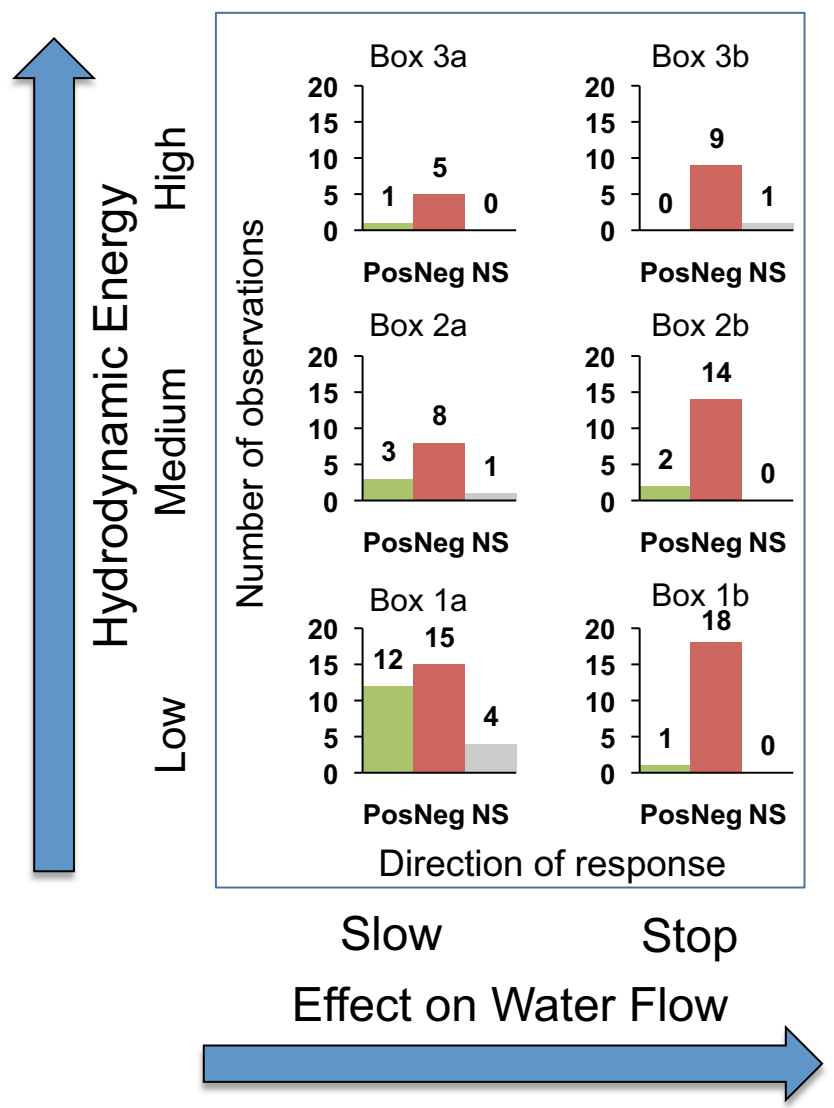

Fig. 5 Ecological effects on species assemblages (E2) reported in studies included in the literature review. The histograms correspond to the six combinations of intended effects on water flow and the hydrodynamic energy of the environment and represented by the boxes in the conceptual model (Fig. 2). In the histogram for each box, the number of significantly positive (green), negative (red), and not significant (NS) (gray) observations is plotted

shorelines (Gittman et al. 2016a). However, the majority of observations in Box 1a were negative and included decreased species diversity and/or abundance for a wide range of assemblages including microbial communities (Bernhard et al. 2012), primary producers (e.g., Sturdevant et al. 2002; O'Connor et al. 2011), infaunal invertebrates (e.g., Peterson et al. 2000; Seitz et al. 2006; Bilkovic and Mitchell 2013), nekton and fish (Bilkovic 2011; Boys et al. 2012; Lowe and Peterson 2014, 2015) and waterbirds (Bolduc and Afton 2003). In Box $1 \mathrm{~b}$, negative responses to armoring dominated the results with decreases in diversity and abundance reported for mangroves (Anthony and Gratiot 2012; Heatherington and Bishop 2012), salt marsh vegetation (Bozek and Burdick 2005), invertebrates (Seitz et al. 2006; Lawless and Seitz 2014; Swamy et al. 2002), and nekton and fish (e.g., Balouskus and Targett 2016; Lowe and Peterson 2014, 2015).

For medium-energy environments, studies of structures designed to slow water (Box 2a) had mixed results, but again, negative impacts made up the majority (75\%) of the reports, including impacts on invertebrates (Morley et al. 2012; Dethier et al. 2016) and on nekton and fish (Scyphers et al. 2015; Torre and Targett 2016). The few positive results were primarily associated with epifauna on the armoring structures themselves (Toft et al. 2013; Drexler et al. 2014) or in one case fish (Toft et al. 2007). For Box 2b, observations were almost entirely negative, with bulkheads and seawalls, resulting in reductions in invertebrates (Sobocinski et al. 2010; Rolet et al. 2015; Dethier et al. 2016; Heerhartz et al. 2016), fish (e.g., Bilkovic and Roggero 2008; Munsch et al. 2014; Scyphers et al. 2015), and even terrapins (Isdell et al. 2015).

Effects on species distribution were again almost entirely negative for armoring structures in high-energy environments (Boxes 3a and 3b). Studies classified in Box 3a found that the presence of armoring depressed invertebrate diversity and abundance (e.g., Moschella et al. 2005; Martins et al. 2009; Bacchiocchi and Airoldi 2003) and also facilitated invasive species (Vaselli et al. 2008). The sole positive result for Box 3 a was reported for benthic diversity and for fish associated with offshore breakwaters (Martin et al. 2005). For Box 3b, all results were negative including responses by coastal dune plants (Rodil et al. 2015), infaunal invertebrates (e.g., Lucrezi et al. 2010; Jaramillo et al. 2012), and birds (Dugan et al. 2008).

Armoring was associated with declines in both species diversity and species abundance across all soft sediment environments and structure types. The majority of observations in all six boxes of our conceptual model were negative, and positive results were most often associated with structures designed to slow water. Although our synthesis is limited by the literature available, this outcome is in general agreement with the predictions of our conceptual model, with negative results predominating ( $\geq 86 \%$ ) in studies of armoring structures designed to stop water flow at all hydrodynamic energy levels (Boxes 1b, 2b, and 3b). For the structures designed to slow water flow, positive results made up $39 \%$ of the reports in Box 1a, 25\% in Box 2a, and 17\% in Box $3 \mathrm{a}$.

\section{E3: Trophic Structure}

Trophic structure and food webs were among the least studied ecological response to armoring found in our review (Table 2). Studies included in this category evaluated variables such as the number of trophic categories, prey availability, shifts in diet, and predator abundance, including fish, birds, and marine mammals. A total of only 18 trophic structure effects were identified, with the majority of studies occurring in lowenergy habitats (10 in salt marshes or tidal creeks and 1 in mangroves), 4 in medium-energy habitats and 3 in highenergy beaches. More of these studies evaluated structures placed to stop (11) as opposed to slow (7) water. A majority 
of the significant responses were considered negative (11), with only 5 reports of positive responses.

Across the boxes of the conceptual model (Table 2), we found mixed results for Box 1a: salt marsh habitats with riprap armoring and sills in the Chesapeake Bay were found to have fewer trophic levels (e.g., Bilkovic and Mitchell 2013). However, living shorelines (Gittman et al. 2016a) and sills in North Carolina (Wong et al. 2011) were reported to maintain higher trophic levels and oyster reefs were associated with increased prey for fishes (Grabowski et al. 2005). For Box 1b, the presence of bulkheads and levees were found to reduce prey availability and result in diet shifts for nekton in marshes (e.g., Lowe and Peterson 2015), although Wong et al. (2011) reported that bulkheads had a positive effect due to epifaunal colonization. For Box 2b, Munsch et al. (2015) documented different food availability and consumption by juvenile salmon adjacent to seawalls, and Jackson et al. (2015) found that shorebirds preferred to forage at unarmored sites. There was only one study in Box 3a: Martin et al. (2005) observed an increase in the number of trophic groups (fish) near a lowcrested armoring structure. For Box $3 \mathrm{~b}$, significantly reduced diversity (50\% lower) and abundance (66\% lower) of shorebirds, key intertidal predators, as well as $75 \%$ fewer gulls and $86 \%$ fewer seabirds were reported on California beaches where seawalls were present (Dugan and Hubbard 2006; Dugan et al. 2008).

Although there are relatively few observations available for trophic structure and food web responses to shore-parallel armoring, the majority of results $(\geq 75 \%)$ in studies of armoring structures designed to stop water flow (Boxes $1 \mathrm{~b}$, $2 \mathrm{~b}$, and $3 \mathrm{~b}$ ) were negative, whereas positive results comprised half of the results in Box 1a and 100\% in Box 3a (Table 2), an outcome in general agreement with the predictions of our conceptual model.

\section{E4: Nutrient Cycling}

The effects of coastal armoring on nutrient cycling have not been widely documented, with a total of only 18 reports in our review (Table 2). The response variables considered in the studies included nutrient concentrations, rate measurements (i.e., denitrification), organic matter composition, and oxygen levels. The majority of these observations were studies of lowenergy environments ( 15 in salt marshes and tidal creeks and 1 in mangroves) with only a few in medium-energy habitats (2) and none for higher-energy open coast environments. Most of these observations were for armoring structures placed to slow (11) as opposed to stop (7) water. A majority of the significant responses to armoring related to nutrient cycling were considered negative (14), with only 2 reports of positive responses.

Across the boxes of our conceptual model, we found the highest number of observations for Box 1a (Table 2). These were primarily negative. For example, salt marsh
Box 3a Box 3b

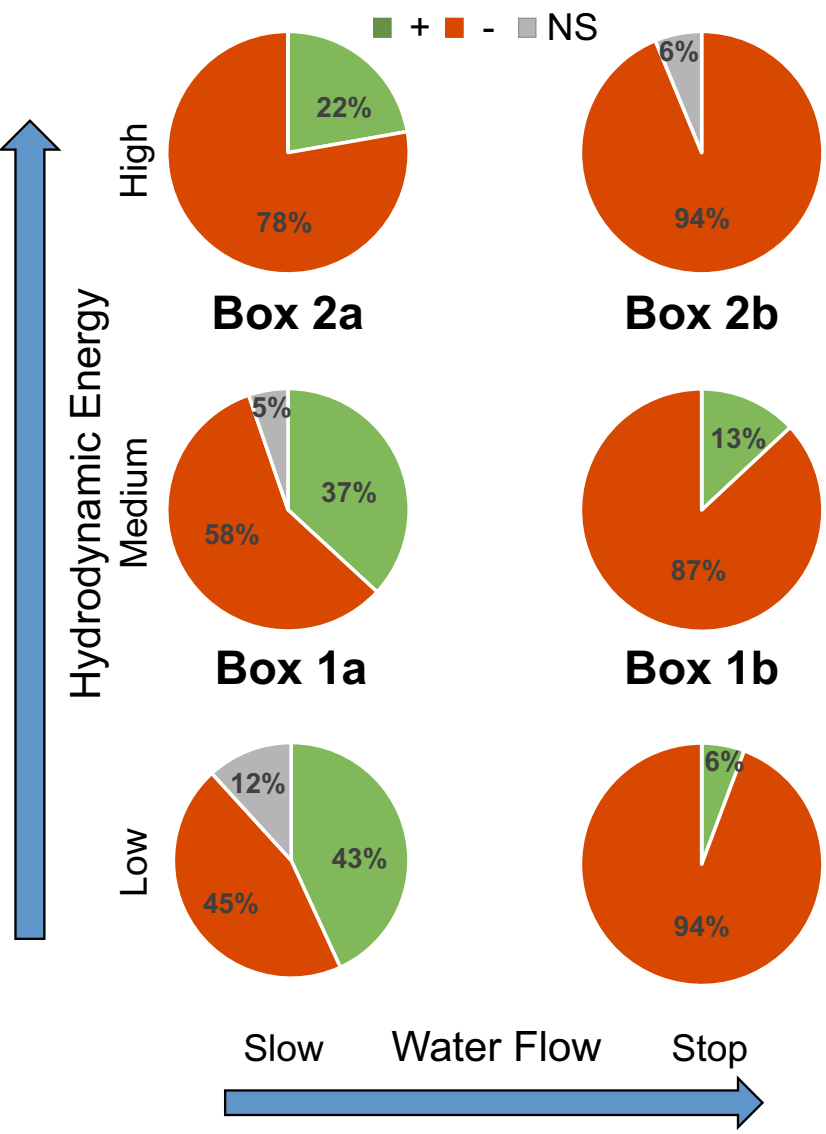

Fig. 6 Summary of the direction of ecological responses $(+/-)$ of combined observations for habitat distribution (E1) and species assemblages (E2) reported in studies in the literature review. The pie charts correspond to the six combinations of intended effects on water flow and the hydrodynamic energy represented by the boxes in the conceptual model (Fig. 2). In the pie chart for each box, the percentage of significantly positive (green), negative (red), and not significant (NS) (gray) observations are plotted

impoundments were associated with declines in dissolved oxygen levels and salinity (Bolduc and Afton 2004) and lower rates of nutrient accumulation (Sturdevant et al. 2002). Several studies documented reductions in sediment organic matter or total organic carbon and nitrogen in association with different armoring structures (sills, revetments, and impoundments) in salt marshes (e.g., Bryant and Chabreck 1998; Peterson et al. 2000; Currin et al. 2008; Bilkovic and Mitchell 2013). In Box 1b, lower organic carbon concentrations were again observed in association with structures (Peterson et al. 2000), and Windham-Myers et al. (2013) found that the reduction in tidal flushing created by the presence of an impoundment resulted in anoxia and the buildup of reduced sulfur. Working in a mangrove system, Dick and Osunkoya (2000) found reduced leaf litter decomposition and greater retention of carbon, nitrogen, and phosphorus on the landward side of tidal floodgate structures. Invasive algae 
growing on bulkheads and revetments in salt marshes were associated with increased $\mathrm{N}_{2}$ production and represented the positive observations reported for Boxes $1 \mathrm{a}$ and $1 \mathrm{~b}$ (Geraldi et al. 2014). There was only one study for Box $2 \mathrm{a}$, wherein Morley et al. (2012) saw an increase in temperature at armored sites, and there was one study for Box $2 b$, wherein lower sediment organic carbon was observed in association with areas with more shoreline armoring in a developed river estuary (Partyka and Peterson 2008).

Although there are relatively few observations available for evaluating the response of nutrient cycling to armoring, the majority of results $(>80 \%)$ were negative for studies of armoring structures designed to either stop or to slow water in medium-energy environments (Boxes $2 \mathrm{a}$ and $2 \mathrm{~b}$ ). The few positive results were reported only for low-energy environments (Boxes 1a and 1b) (Table 2).

\section{E5: Productivity}

The effects of coastal armoring on productivity were not well represented in the literature review, with a total of only 13 observations (Table 2). These studies measured effects including the primary production of macroalgae, plants, and microphytobenthos and the secondary production of higher organisms. The majority of these observations were reported for low-energy environments (10 in salt marsh and tidal creeks and 1 in mangroves) with none in medium-energy environments and only 2 in high-energy beach environments (Table 2). The dominance of primary producers in salt marshes compared to beaches and other shore types may explain some of this disparity. These studies were balanced between armoring structures placed to slow (7) as opposed to stop (6) water. For the limited number of studies (13) examining the effects of shoreline armoring on productivity, the majority of results (69\%) were negative (9), 2 were positive, and 2 were found to have no change (Table 2). All the positive and no change results for this ecological response category were observed in low-energy environments (Boxes 1a and 1b).

Although there were relatively few observations of armoring effects on productivity, four of the six boxes from our conceptual model (Table 2) were represented in the literature review. For Box 1a, riprap, sill, and impoundment structures were associated with reduced productivity and biomass of plants and algae (O'Connor et al. 2011; Sturdevant et al. 2002) and reduced cover, growth, and biomass of marsh grass (Spartina spp.) (Currin et al. 2008; Bilkovic and Mitchell 2013). Reductions in productivity in salt marsh (Freiss et al. 2008) and mangrove (Heatherington and Bishop 2012) ecosystems were also associated with seawalls (Box 1b). However, Wong et al. (2011) observed positive responses to armoring in low-energy habitats, reporting that the presence of both sills (Box 1a) and bulkheads (Box 1b) led to greater secondary production in salt marshes in North Carolina than in habitats without the added structure. The single study for a sandy beach (Rodil et al. 2015) concluded that the presence of both revetments and seawalls (Box 3b) limited the growth and development of coastal strand and dune vegetation.

\section{E6: Connectivity}

Despite the importance of connectivity, this was the least documented ecological response in our literature review, with a total of only seven observations (Table 2). The studies included in this ecological response evaluated effects of armoring on the exchange of materials, mobile organisms, and propagules across shore zones and ecosystems. The majority of these observations were reported for low- and medium-energy environments, with one in salt marshes and tidal creeks and one in mangroves, four in medium-energy habitats, and one in a high-energy beach environment. Most of these studies evaluated armoring structures placed to stop (five) as opposed to slow (two) water (Table 2). All observations related to effects of shoreline armoring on connectivity were negative, including those for structures designed to stop or to slow water flow.

Although there were relatively few observations of armoring effects on connectivity, five of the six boxes from our conceptual model (Table 2) were represented. The addition of armoring structures in low-energy environments to limit the flow of water (Box 1a) restricted the passage of fish and crustaceans (Boys et al. 2012). In Box 1b, the addition of a seawall reduced availability and prevented movement of propagules in a mangrove ecosystem (Anthony and Gratiot 2012). In medium-energy soft sediment environments, Box 2a, the only study available found that riprap armoring significantly limited material transfer from adjacent marine and terrestrial habitats to the shoreline (Heerhartz et al. 2014). For Box 2b, results were again negative, indicating that bulkheads and seawalls limited material transfer and restricted the movement of fish species, including economically valuable salmon (Heerhartz et al. 2014; Munsch et al. 2014; Heerhartz and Toft 2015). In the one example for a high-energy environment (Box 3b), seawalls were found to eliminate the upper intertidal zones of sandy beaches, thereby reducing material transfer and retention in the form of marine macrophyte drift (Dugan and Hubbard 2006). These results indicate the presence of an armoring structure can prevent the passage of organisms, and in many cases it also reduces the deposition and retention of drift material and key subsidies, such as macrophyte wrack.

Although only a few studies examined the effects of shoreline armoring on connectivity, the negative effect of a loss of connectivity across zones and ecosystems and the associated habitat fragmentation and restriction of landward movement was reported in all soft sediment 
environments and in all of the boxes with results represented in our conceptual model.

\section{Summary of Ecological Effects}

A total of 207 effects were evaluated across the six boxes of the conceptual model. They were split fairly evenly between results of studies of structures designed to slow water (106) and those designed to stop it (101). Although the majority of studies were conducted in low-energy environments (75 in Box 1a and 48 in Box 1b), all boxes of the conceptual model were represented (Table 2). Across all 207 effects evaluated, $71 \%$ were reported to be significantly negative, $22 \%$ were significantly positive, and only $7 \%$ were not significant (Table 2).

Habitat distribution (E1) and species assemblage (E2) were the two ecological responses with sufficient results to allow comparison across all six boxes of the conceptual model (Figs. 4 and 5). These two ecological effects were also often closely related (i.e., when there is a shift in habitat that often has an effect on species assemblage) due to the important influence of habitat on species distributions. When we combined the results for these two responses to provide a broader summary (Fig. 6), the percentage of negative responses reported within each hydrodynamic energy category were greater for structures designed to stop water flow (Boxes $1 \mathrm{~b}, 2 \mathrm{~b}$, and 3b) (16 to $49 \%$ greater) than for those designed to slow water flow (Boxes 1a, 2a, and 3a). The percentage of negative responses reported also increased with increasing hydrodynamic energy for structures designed to slow water flow ( $45 \%$ in Box 1a, 58\% Box 2a, and 78\% in Box 3a) but were more uniformly high for those designed to stop water flow across environments (94\% in Box $1 \mathrm{~b}, 87 \%$ in Box $2 \mathrm{~b}$, and $94 \%$ in Box 3b) (Fig. 6).

The percentage of positive ecological effects for the combined results for E1 and E2 were largely the converse of the negative results. Within a given hydrodynamic energy environment, the percentage of positive results were greater for structures built to slow as opposed to stop or prevent water flow (Fig. 6). For structures designed to slow water flow, the percentage of positive ecological effects clearly declined with increasing hydrodynamic energy, from $42 \%$ in low- to $22 \%$ in high-energy environments. This trend for positive effects was less clear for structures designed to stop water flow as all boxes had a very low percentage of positive effects, and no positive results were reported in high-energy environments. Many of the positive results reported were from studies of constructed oyster reef and living shoreline structures, although a number of positive effects we tallied were associated with the colonization of new and novel hard substrate habitats provided by armoring or shoreline protection structures.
Collectively, the combined results for E1 and E2 in Fig. 6 were consistent with our predictions that the ecological effects of shoreline armoring would be greater for structures designed to stop as opposed to slow water flow and provide some evidence that ecological effects may intensify with increasing hydrodynamic energy of the environment or setting. They also suggest that the purpose of the structure with respect to water flow has a greater effect on ecological responses than the hydrodynamic energy of the soft sediment environment.

\section{Discussion}

As indicated by the number of recent papers in our literature review (as well as the other papers included in this special issue), the ecological effects of shoreline hardening are receiving increased attention. Placing this information in the framework of our conceptual model enabled us to scale the ecological effects of shore-parallel armoring and allowed comparisons across a range of soft sediment ecosystems and armoring structures. However, our review revealed major gaps in knowledge and highlighted the fact that existing information on ecological responses to armoring is unevenly distributed across habitat types and does not necessarily cover the range of potential environmental and armoring contexts. We found the majority of studies have been conducted in low-energy systems, particularly salt marshes, with much less attention to beaches and open coast shores. There was also a notable dearth of studies in mangrove systems. The distribution of studies across the various ecological responses were largely focused on changes in habitat and species distribution, leaving crucial gaps in our understanding of how the presence of shoreline armoring affects key ecological responses of nutrient cycling, connectivity, productivity, and trophic structure. Filling these gaps will allow a far more complete evaluation and synthesis of the ecological responses to shoreline armoring than was possible here.

Despite the gaps in knowledge, the majority of studies in our literature review reported significantly negative effects of shoreline armoring in all six categories of ecological responses that we evaluated. Shoreline armoring of a wide array of structure types resulted in habitat loss, shifts in species assemblages and trophic structure, changes in nutrient cycling, reduced productivity, and the loss of connectivity in soft sediment environments across all boxes of our conceptual model. Negative effects of armoring on habitat and connectivity have the potential to trigger impacts in all the other ecological responses we evaluated.

Reported positive effects of armoring were far fewer and were less evenly distributed across our six ecological response categories and the boxes of the conceptual model. Although low, the proportion of positive effects reported was generally 
higher in the ecological response categories of habitat distribution (E1), species assemblages (E2), and trophic structure (E3) than in the other three categories (E4-E6) (Table 2). This pattern seems consistent with the colonization and use of the novel hard substrate habitats provided by armoring structures in otherwise soft-bottomed ecosystems by a variety of organisms that prefer hard substrates (e.g., Meyer et al. 1997; Davis et al. 2002; Swann 2008; Browne and Chapman 2011). However, facilitation of species distributions by armoring structures can be ecologically negative if non-native invasive species are involved because such species may preferentially use artificial structures as stepping stones, potentially increasing their spread to new areas (e.g. Airoldi et al. 2005, Bulleri and Airoldi 2005, Tyrell and Byers 2007).

Placing the results from our literature review in the framework of our conceptual model enabled us to coarsely scale the ecological effects of armoring and allowed comparisons across a range of soft sediment ecosystems and structures. The percentage of negative responses varied clearly with the intended purpose of armoring structures on water flow, increasing from those designed to slow water flow to those designed to stop water flow within a given hydrodynamic energy level. The distribution of results among the six boxes in our conceptual model was consistent with our prediction that the ecological effects of shoreline armoring would be greater for structures designed to stop as opposed to slow water. Although less clear-cut, there was also evidence that ecological effects may intensify with increasing hydrodynamic energy of the environment. Overall, our results suggest that the purpose of the structure with respect to water flow has a greater effect on ecological responses than the hydrodynamic energy of the soft sediment environment (Table 2, Fig. 6). This finding has potential implications for refining the design and permeability of armoring structures in ways that can reduce ecological impacts, particularly in low-energy environments.

One of the limitations of the results reported here is that our synthesis relies on the reported significance of responses in studies with a wide range of sample sizes. Using effect size, which takes sample size and variance into account, can provide a normalized measure that can be more quantitatively compared across studies. The recent paper by Gittman et al. (2016b), which compared effect sizes for ecological responses to three armoring structure types (breakwaters, riprap revetments, and seawalls), concluded that greater ecological impacts on biodiversity and abundance were associated with seawalls compared to revetments and breakwaters. This result is in agreement with that predicted by our conceptual model for structures designed to stop vs. slow water flow. However, their meta-analysis did not address any possible differences with respect to the different hydrodynamic energy levels of soft sediment environments affected by armoring. In our review, the ecological response of species assemblages (E2) was the only category with sufficient data to allow comparisons of effect sizes across most of our conceptual model (five of six boxes) (see Table S3 for complete results). We found the lowest effect sizes for armoring structures in low-energy environments (Boxes 1a and 1b) with two- to five-fold higher effect sizes in medium- and high-energy environments, a result that is broadly consistent with our predictions. These results, along with those of Gittman et al. (2016b), suggest that comparing effect sizes from studies designed to make common measurements across all six boxes of our conceptual model could advance synthesis and allow more general predictions of ecological responses to armoring across soft sediment ecosystems and structure types.

Another refinement of our conceptual model would be to incorporate quantitative information on permeability and hydrodynamic energy of armoring structures. We divided our conceptual model into six boxes for heuristic purposes but recognize that both axes are continuous variables that can be scaled in terms of water flow (i.e., $\mathrm{m}^{3} \mathrm{~s}^{-1}$ ) and energy (i.e.,

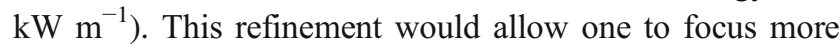
precisely on the hydrodynamic energy at the structure and how impacts might be influenced by characteristics, such as tidal elevation of the structure. For example, the lower an armoring structure is located with respect to high water levels, the greater the associated physical impacts (Weggel 1988, Wiegel 2002a, b, c). Our conceptual model would predict ecological effects to scale similarly with decreasing intertidal elevation of the structure, which would move it up the hydrodynamic energy axis and consequently magnify the effects it exerts on the coastal ecosystem. This also implies that as existing armoring structures effectively move lower on the shore profile with rising sea level, their ecological impacts would be expected to increase. Considering additional attributes of armoring structures such as size, construction material (e.g., Nordstrom 2014) or the amount of surface area that is partially or completely submerged would provide fruitful ways to further refine and increase the specificity of the predictions of our conceptual model.

This effort provides a needed first step in generating discussion and motivating synthesis that can lead to a comprehensive framework for scaling the ecological effects of shoreline armoring across a range of coastal soft sediment ecosystems. The conceptual model allowed us to evaluate predictions regarding the direction and relative ecological impacts of shoreparallel armoring structures in different soft sediment environments based on relatively simple criteria. The results of our literature search were largely consistent with the predictions of our conceptual model and suggest that such crossenvironment generalizations are possible and may have implications for balancing the protection of coastal infrastructure with the conservation of coastal ecosystems. However, our analysis also highlights substantial research gaps and the need for comprehensive studies designed to make systematic comparisons of the ecological effects of shoreline armoring across structure types and environments. The results from these types 
of comprehensive efforts could be useful for assessing the relative ecological costs of various approaches to shoreline armoring and for informing the development of strategies to minimize their impacts on coastal ecosystems (Nordstrom 2014, 2016). Increasing the ability to generalize ecological responses to shoreline armoring across soft sediment coastal ecosystems and structure types is especially important, given that the motivation to build additional armoring in soft sediment environments is expected to continue to increase in response to sea level rise, coastal development, and other pressures.

Acknowledgements This study was supported by an LTER Network synthesis working group award from the National Science Foundation and made possible by participants from the Georgia Coastal Ecosystems, Virginia Coast Reserve, Santa Barbara Coastal, Plum Island Ecosystems, and Florida Coastal Everglades Long Term Ecological Research (LTER) projects. We thank Karen McGlathery and the staff of the Virginia Coast Reserve LTER and the Anheuser-Busch Coastal Research Center, University of Virginia, and the staff of the Skidaway Institute of Oceanography, University of Georgia and the Georgia Coastal Ecosystems LTER for hosting the working group meetings. We are grateful to the LTER Network Office for the logistical support for the working group meetings. We gratefully acknowledge the National Science Foundation's support of the Long Term Ecological Research programs of Santa Barbara Coastal LTER (Award No. OCE-1232779), the Georgia Coastal Ecosystems LTER (Award No. OCE 12-37140), and the Virginia Coast Reserve LTER (Grant No. 1237733). We thank the National Science Foundation (Award No. OCE 14-58845) for support during manuscript preparation. Any opinions, findings, and conclusions or recommendations expressed in this material are those of the authors and do not necessarily reflect the views of the National Science Foundation (NSF).

Open Access This article is distributed under the terms of the Creative Commons Attribution 4.0 International License (http://creativecommons. org/licences/by/4.0/), which permits use, duplication, adaptation, distribution and reproduction in any medium or format, as long as you give appropriate credit to the original author(s) and the source, provide a link to Creative Commons license and indicate if changes were made.

\section{References}

Airoldi, Laura, Marco Abbiati, Michael W. Beck, Stephen J. Hawkins, Per R. Jonsson, Daniel Martin, Paula S. Moschella, Andreas Sundelöf, Richard C. Thompson, and Per Åberg. 2005. An ecological perspective on the deployment and design of low-crested and other hard coastal defence structures. Coastal Engineering 52: 1073-1087.

Anthony, Edward J., and Nicolas Gratiot. 2012. Coastal engineering and large-scale mangrove destruction in Guyana, South America: averting an environmental catastrophe in the making. Ecological Engineering 47: 268-273.

Bacchiocchi, Francesca, and Laura Airoldi. 2003. Distribution and dynamics of epibiota on hard structures for coastal protection. Estuarine Coastal and Shelf Science 56: 1157-1166.

Baily, Brian, and Alistair W. Pearson. 2007. Change detection mapping and analysis of salt marsh areas of central southern England from Hurst Castle Spit to Pagham Harbour. Journal of Coastal Research 23: $1549-1564$
Balouskus, Richard G., and Timothy E. Targett. 2012. Egg deposition by Atlantic Silverside, Menidia menidia: substrate utilization and comparison of natural and altered shoreline type. Estuaries and Coasts 35: $1100-1109$.

Balouskus, Richard G., and Timothy E. Targett. 2016. Fish and blue crab density along a riprap-sill-hardened shoreline: comparisons with Spartina marsh and riprap. Transactions of the American Fisheries Society 145: 766-773.

Bernhard, Anne E., David Marshall, and Lazaros Yiannos. 2012. Increased variability of microbial communities in restored salt marshes nearly 30 years after tidal flow restoration. Estuaries and Coasts 35: 1049-1059.

Bilkovic, Donna M. 2011. Response of tidal creek fish communities to dredging and coastal development pressures in a shallow-water estuary. Estuaries and Coasts 34: 129-147.

Bilkovic, Donna M., and Molly M. Mitchell. 2013. Ecological tradeoffs of stabilized salt marshes as a shoreline protection strategy: effects of artificial structures on macrobenthic assemblages. Ecological Engineering 61: 469-481.

Bilkovic, Donna M., and Molly M. Roggero. 2008. Effects of coastal development on nearshore estuarine nekton communities. Marine Ecology Progress Series 358: 27-39.

Bilkovic, Donna M., Molly Mitchell, Pam Mason, and Karen Duhring. 2016. The role of living shorelines as estuarine habitat conservation strategies. Coastal Management44:3, 161-174.

Bolduc, Francois, and Alan D. Afton. 2003. Effects of structural marsh management and salinity on invertebrate prey of waterbirds in marsh ponds during winter on the Gulf Coast Chenier Plain. Wetlands 23: 897-910.

Bolduc, Francois, and Alan D. Afton. 2004. Hydrologic aspects of marsh ponds during winter on the Gulf Coast Chenier Plain, USA: effects of structural marsh management. Marine Ecology Progress Series 266: 35-42.

Boys, Craig A., Frederieke J. Kroon, Tim M. Glasby, Kevin Wilkinson. 2012. Improved fish and crustacean passage in tidal creeks following floodgate remediation. Journal of Applied Ecology 49(1): 223-233.

Bozek, Catherine M., and David M. Burdick. 2005. Impacts of seawalls on saltmarsh plant communities in the Great Bay Estuary, New Hampshire USA. Wetlands Ecology and Management 13: 553-568.

Browne, Mark A., and M. Gee Chapman. 2011. Ecologically informed engineering reduces loss of intertidal biodiversity on artificial shorelines. Environmental Science \& Technology 45: 8204-8207.

Browne, Mark A., and M. Gee Chapman. 2014. Mitigating against the loss of species by adding artificial intertidal pools to existing seawalls. Marine Ecology Progress Series 497: 119-129.

Bryant, John C., and Robert H. Chabreck. 1998. Effects of impoundment on vertical accretion of coastal marsh. Estuaries 21: 416-422.

Bulleri, Fabio, and Laura Airoldi. 2005. Artificial marine structures facilitate the spread of a non-indigenous green alga, Codium fragile ssp. tomentosoides, in the north Adriatic Sea. Journal of Applied Ecology 42: 1063-1072.

Bulleri, Fabio, and Maura G. Chapman. 2010. The introduction of coastal infrastructure as a driver of change in marine environments. Journal of Applied Ecology 47: 26-35.

Charlier, Roger H., Marie Claire P. Chaineux, and Selim Morcos. 2005. Panorama of the history of coastal protection. Journal of Coastal Research 21:(1), 79-111.

Currin, Carolyn A., Priscilla C. Delano, and Lexia M. Valdes-Weaver. 2008. Utilization of a citizen monitoring protocol to assess the structure and function of natural and stabilized fringing salt marshes in North Carolina. Wetlands Ecology and Management 16: 97-118.

Davis, J.L.D., L.A. Levin, and S.M. Walther. 2002. Artificial armored shorelines: sites for open-coast species in a southern California bay. Marine Biology 140: 1249-1262. 
Dethier, Megan N., Wendel W. Raymond, Aundrea N. McBride, Jason D. Toft, Jeffery R. Cordell, Andrea S. Ogston, Sarah M. Heerhartz, and Helen D. Berry. 2016. Multiscale impacts of armoring on Salish Sea shorelines: evidence for cumulative and threshold effects. Estuarine Coastal and Shelf Science 175: 106-117.

Dick, Todd M., and Olusegun O. Osunkoya. 2000. Influence of tidal restriction floodgates on decomposition of mangrove litter. Aquatic Botany 68: 273-280.

Drexler, Michael, Melanie L. Parker, Stephen P. Geiger, William S. Arnold, and Pamela Hallock. 2014. Biological assessment of eastern oysters (Crassostrea virginica) inhabiting reef, mangrove, seawall, and restoration substrates. Estuaries and Coasts 37: 962-972.

Dugan, Jenifer E., and David M. Hubbard. 2006. Ecological responses to coastal armoring on exposed sandy beaches. Shore \& Beach 74: 10-16.

Dugan, J.E., Airoldi, L., Chapman, M.G., Walker, S. and T.A. Schlacher. 2012. Estuarine and coastal structures: environmental effects: a focus on shore and nearshore structures. In: Human-induced problems (uses and abuses), In: Estuaries and coasts, eds. M. Kennish, M. Elliot, 17-41. Treatise on Estuarine and Coastal Science Vol. 8 Chapter 2, Elsevier.

Dugan, Jenifer E., David M. Hubbard, Iván F. Rodil, David L. Revell, and Stephen Schroeter. 2008. Ecological effects of coastal armoring on sandy beaches. Marine Ecology 29: 160-170.

US Army Corps of Engineers. 2002. Coastal Engineering Manual. Engineer Manual 1110: 2-1100.

Fletcher, Charles H., Robert A. Mullane and Bruce M. Richmond. 1997. Beach loss along armored shorelines on Oahu, Hawaiian Islands. Journal of Coastal Research v.13, no. 1, 209-215.

Freiss, D., I. Möller and T. Spencer. 2008. Case Study: Managed Realignment and the Re-establishment of Saltmarsh Habitat, Freiston Shore, Lincolnshire, United Kingdom. In: The Role of Environmental Management and Eco-Engineering in Disaster Risk Reduction and Climate Change Adaptation, 65-78. Nyon, Switzerland: ProAct Network Association.

Geraldi, Nathan R., Ashley R. Smyth, Michael F. Piehler, and Charles H. Peterson. 2014. Artificial substrates enhance non-native macroalga and N2 production. Biological Invasions 16: 1819-1831.

Gittman, Rachel K., F. Joel Fodrie, Alyssa M. Popowich, Danielle A. Keller, John F. Bruno, Carolyn A. Currin, Charles H. Peterson, and Michael F. Piehler. 2015. Engineering away our natural defenses: an analysis of shoreline hardening in the US. Frontiers in Ecology and the Environment 13: 301-307.

Gittman, Rachel K., Charles H. Peterson, Carolyn A. Currin, F. Joel Fodrie, Michael F. Piehler, and John F. Bruno. 2016a. Living shorelines can enhance the nursery role of threatened estuarine habitats. Ecological Applications 26: 249-263.

Gittman, Rachel K., Alyssa M. Popowich, John F. Bruno, and Charles H. Peterson. 2014. Marshes with and without sills protect estuarine shorelines from erosion better than bulkheads during a category 1 hurricane. Ocean \& Coastal Management 102: 94-102.

Gittman, Rachel. K., Stephen B. Scyphers, Carter S. Smith, Isabelle P. Neylan, and Jonathan H. Grabowski. 2016b. Ecological consequences of shoreline hardening: a meta-analysis. BioScience 66 (9): 763-773.

Grabowski, Jonathan H., A. Randall Hughes, David L. Kimbro, and Margaret A. Dolan. 2005. How habitat setting influences restored oyster reef communities. Ecology 86: 1926-1935.

Griggs, Gary B. 2005a. California's retreating coastline: where do we go from here. In California and the World Ocean 2002, eds. Orville T. Magoon, Hugh Converse, Brian Baird, Beth Jines, Melissa MillerHenson, 121-125. Reston, Virginia: American Society of Civil Engineers.

Griggs, Gary B. 2005b. The impacts of coastal armoring. Shore and beach 73: 13-22.
Griggs, Gary B. 2010. The effects of armoring shorelines - the California experience. In Puget Sound Shorelines and the Impacts of Armoring-Proceedings of a State of the Science Workshop, eds Hugh Shipman, Megan Dethier, Guy Gelfenbaum, Kurt L Fresh, RS Dincola, 77-84. Reston, Virginia: US Geological Survey Scientific Investigations Report 2010-5254.

Hall, Mary J., and Orrin H. Pilkey. 1991. Effects of hard stabilization on dry beach width for New Jersey. Journal of Coastal Research v. 7, no. $3,771-785$.

Hayes, Miles O. 1979. Barrier island morphology as a function of tidal and wave regime. In Barrier Islands, ed. S.P. Leatherman, 1-27. New York: Academic.

Heatherington, C., and Melanie J. Bishop. 2012. Spatial variation in the structure of mangrove forests with respect to seawalls. Marine and Freshwater Research 63: 926-933.

Heerhartz, Sarah M., Megan N. Dethier, Jason D. Toft, Jeffery R. Cordell, and Andrea S. Ogston. 2014. Effects of shoreline armoring on beach wrack subsidies to the nearshore ecotone in an estuarine fjord. Estuaries and Coasts 37: 1256-1268.

Heerhartz, Sarah M., and Jason D. Toft. 2015. Movement patterns and feeding behavior of juvenile salmon (Oncorhynchus spp.) along armored and unarmored estuarine shorelines. Environmental Biology of Fishes 98: 1501-1511.

Heerhartz, Sarah M., Jason D. Toft, Jeffery R. Cordell, Megan N. Dethier, and Andrea S. Ogston. 2016. Shoreline armoring in an estuary constrains wrack-associated invertebrate communities. Estuaries and Coasts 39: 171-188.

Hendon, J. Read, Mark S. Peterson, and Bruce H. Comyns. 2000. Spatiotemporal distribution of larval Gobiosoma bosc in waters adjacent to natural and altered marsh-edge habitats of Mississippi coastal waters. Bulletin of Marine Science 66: 143-156.

Hieu, Phung Dang, and Phan Ngoc Vinh. 2012. Numerical study of wave overtopping of a seawall supported by porous structures. Applied Mathematical Modelling 36: 2803-2813.

Isdell, Robert E., Randolph M. Chambers, Donna M. Bilkovic, and Matthias Leu. 2015. Effects of terrestrial-aquatic connectivity on an estuarine turtle. Diversity and Distributions 21: 643-653.

Jackson, Nancy L., Karl F. Nordstrom, Sherestha Saini, and David R. Smith. 2015. Influence of configuration of bulkheads on use of estuarine beaches by horseshoe crabs and foraging shorebirds. Environmental Earth Sciences 74: 5749-5758.

Jaramillo, Eduardo, Jenifer E. Dugan, David M. Hubbard, Daniel Melnick, Mario Manzano, Cristian Duarte, Cesar Campos, and Roland Sanchez. 2012. Ecological implications of extreme events: footprints of the 2010 earthquake along the Chilean coast. PloS One 7: e35348.

Karim, Mohammed Fazlul, Katsutoshi Tanimoto, and Phung Dang Hieu. 2009. Modelling and simulation of wave transformation in porous structures using VOF based two-phase flow model. Applied Mathematical Modelling 33: 343-360.

Kraus, Nicholas C., and William G. McDougal. 1996. The effects of seawalls on the beach: part I, an updated literature review. Journal of Coastal Research v. 12, no. 3, 691-701.

Lawless, Amanda S., and Rochelle D. Seitz. 2014. Effects of shoreline stabilization and environmental variables on benthic infaunal communities in the Lynnhaven River System of Chesapeake Bay. Journal of Experimental Marine Biology and Ecology 457: 41-50.

Lowe, Michael R., and Mark S. Peterson. 2014. Effects of coastal urbanization on salt-marsh faunal assemblages in the northern Gulf of Mexico. Marine and Coastal Fisheries 6: 89-107.

Lowe, Michael R., and Mark S. Peterson. 2015. Body condition and foraging patterns of nekton from salt marsh habitats arrayed along a gradient of urbanization. Estuaries and Coasts 38: $800-812$.

Lucrezi, Serena, Thomas A. Schlacher, and Wayne Robinson. 2010. Can storms and shore armouring exert additive effects on sandy-beach 
habitats and biota? Marine and Freshwater Research 61: 951-962.

Mallayachari, V., and V. Sundar. 1994. Reflection characteristics of permeable seawalls. Coastal Engineering 23: 135-150.

Martin, Daniel, Fabio Bertasi, Marina A. Colangelo, Mindert de Vries, Matthew Frost, Stephen J. Hawkins, Enrique Macpherson, Paula S. Moschella, M. Paola Satta, and Richard C. Thompson. 2005. Ecological impact of coastal defence structures on sediment and mobile fauna: evaluating and forecasting consequences of unavoidable modifications of native habitats. Coastal Engineering 52: 1027-1051.

Martins, Gustavo M., André F. Amaral, Francisco M. Wallenstein, and Ana I. Neto. 2009. Influence of a breakwater on nearby rocky intertidal community structure. Marine Environmental Research 67: 237-245.

McPherson, Martina L. 2009. Adaptation to sea-level rise in North Carolina. Masters Thesis, Nicholas School of the Environment, Duke University, Durham: North Carolina.

Meyer, David L., Edward C. Townsend, and Gordon W. Thayer. 1997. Stabilization and erosion control value of oyster cultch for intertidal marsh. Restoration Ecology 5: 93-99.

Miles, J. R., Russell, P. E., and D. A. Huntley. 2001. Field measurements of sediment dynamics in front of a seawall. Journal of Coastal Research 17:(1), 195-206.

Morley, Sarah A., Jason D. Toft, and Karrie M. Hanson. 2012. Ecological effects of shoreline armoring on intertidal habitats of a Puget Sound urban estuary. Estuaries and Coasts 35: 774-784.

Moschella, P. S., M. Abbiati, P. Aberg, L. Airoldi, L. M. Anderson, F. Bacchiocchi, F. Bulleri, G. E. Dinesen, M. Frost, E. Gacia, L. Granhag, P. R. Jonsson, M. P. Satta, A. Sundelof, R.C. Thompson and S. J. Hawkins. 2005. Low-crested coastal defence structures as artificial habitats for marine life: using ecological criteria in design. Coastal Engineering 52: 1053-1071.

Munsch, Stuart H., Jeffery R. Cordell, and Jason D. Toft. 2016. Fine-scale habitat use and behavior of a nearshore fish community: nursery functions, predation avoidance, and spatiotemporal habitat partitioning. Marine Ecology Progress Series 557: 1-15.

Munsch, Stuart H., Jeffery R. Cordell, Jason D. Toft, and Erin E. Morgan. 2014. Effects of seawalls and piers on fish assemblages and juvenile salmon feeding behavior. North American Journal of Fisheries Management 34: 814-827.

Neumann, Barbara, Athanasios T. Vafeidis, Juliane Zimmermann, and Robert J. Nicholls. 2015. Future coastal population growth and exposure to sea-level rise and coastal flooding - a global assessment. PloS One 10: $\mathrm{e} 0118571$.

Nordstrom, Karl F. 2000. Beaches and dunes of developed coasts. Cambridge: Cambridge University Press.

Nordstrom, Karl F. 2014. Living with shore protection structures: a review. Estuarine, Coastal and Shelf Science 150: 11-23.

Nordstrom, Karl F. 2016. Facilitating landform migration by removing shore protection structures: opportunities and constraints. Environmental Science \& Policy. doi:10.1016/j.envsci.2016.07.012.

O'Connor, Mary I., Christy R. Violin, Andrea Anton, Laura M. Ladwig, and Michael F. Piehler. 2011. Salt marsh stabilization affects algal primary producers at the marsh edge. Wetlands Ecology and Management 19: 131-140.

Partyka, M.L., and M.S. Peterson. 2008. Habitat quality and salt-marsh species assemblages along an anthropogenic estuarine landscape. Journal of Coastal Research 1570-1581.

Patrick, Christopher J., Donald E. Weller, Xuyong Li, and Micah Ryder. 2014. Effects of shoreline alteration and other stressors on submerged aquatic vegetation in subestuaries of Chesapeake Bay and the mid-Atlantic coastal bays. Estuaries and Coasts 37: 1516-1531.

Patrick, Christopher J., Donald E. Weller, and Micah Ryder. 2016. The relationship between shoreline armoring and adjacent submerged aquatic vegetation in Chesapeake Bay and nearby Atlantic Coastal Bays. Estuaries and Coasts 39: 158-170.
Perkins, Matthew J., Terence P.T. Ng, David Dudgeon, Timothy C. Bonebrake, Kenneth M.Y. Leung. 2015. Conserving intertidal habitats: What is the potential of ecological engineering to mitigate impacts of coastal structures? Estuarine, Coastal and Shelf Science 167: 504-515.

Peters, Joseph R., Lauren A. Yeager, and Craig A. Layman. 2015. Comparison of fish assemblages in restored and natural mangrove habitats along an urban shoreline. Bulletin of Marine Science 91: $125-139$.

Peterson, M.S., B.H. Comyns, J.R. Hendon, P.J. Bond, and G.A. Duff. 2000. Habitat use by early life-history stages of fishes and crustaceans along a changing estuarine landscape: differences between natural and altered shoreline sites. Wetlands Ecology and Management 8: 209-219.

Piazza, Bryan P., Patrick D. Banks, and Megan K. La Peyre. 2005. The potential for created oyster shell reefs as a sustainable shoreline protection strategy in Louisiana. Restoration Ecology 13: 499-506.

Piersma, T. 2009. Threats to intertidal soft sediment ecosystems. In: Water policy in the Netherlands: integrated management in a densely populated delta, eds. Stijn Reinhard, Henk Folmer, 57-69. Resources for the Future, Washington D.C.

Pister, Benjamin. 2009. Urban marine ecology in southern California: the ability of riprap structures to serve as rocky intertidal habitat. Marine Biology 156: 861-873.

Pilkey, O.H., Young, R., Longo, N., and A. Coburn. 2012. Rethinking living shorelines. White paper, Program for the Study of Developed Shorelines, Western Carolina University, March 1, 2012, https:/ livingshorelinesacademy.org/index.php/resources/literature/item/ pilkey-et-al-2012.

Powers, Sean P., Charles H. Peterson, Jonathan H. Grabowski, and Hunter S. Lenihan. 2009. Success of constructed oyster reefs in no-harvest sanctuaries: implications for restoration. Marine Ecology Progress Series 389: 159-170.

Reise, Karstan. 2001. Ecological comparisons of sedimentary shores. Ecological Studies Vol 151. Berlin Heidelberg: Springer-Verlag.

Rippon, Stephen. 2001. The transformation of coastal wetlands: exploitation and management of marshland landscapes in North West Europe during the roman and medieval periods. London: British Academy. Oxford University Press, Oxford

Rizkalla, Carol E., and Anne Savage. 2011. Impact of seawalls on loggerhead sea turtle (Caretta caretta) nesting and hatching success. Journal of Coastal Research 27: 166-173.

Rodil, Iván F., Eduardo Jaramillo, David M. Hubbard, Jenifer E. Dugan, Daniel Melnick, and Carlos Velasquez. 2015. Responses of dune plant communities to continental uplift from a major earthquake: sudden releases from coastal squeeze. PloS One 10: e0124334.

Rolet, Céline, Nicolas Spilmont, Dominique Davoult, Eric Goberville, and Christophe Luczak. 2015. Anthropogenic impact on macrobenthic communities and consequences for shorebirds in northern France: a complex response. Biological Conservation 184: 396-404.

Ruggiero, Peter. 2010. Impacts of shoreline armoring on sediment dynamics. In: Puget Sound Shorelines and the Impacts of ArmoringProceedings of a State of the Science Workshop, May 2009, eds Hugh Shipman, Megan Dethier, Guy Gelfenbaum, Kurt L Fresh, RS Dincola, 179-186. Reston, Virginia: US Geological Survey Scientific Investigations Report 2010-5254.

Runyan, K., and G.B. Griggs. 2003. The effects of armoring seacliffs on the natural sand supply to the beaches of California. Journal of Coastal Research v. 19, no. 2, 336-347.

Scyphers, Steven B., J. Steven Picou, Robert D. Brumbaugh, and Sean P. Powers. 2014. Integrating societal perspectives and values for improved stewardship of a coastal ecosystem engineer. Ecology and Society 19: 38. 
Scyphers, Steven B., Sean P. Powers, and Kenneth L. Heck Jr. 2015. Ecological value of submerged breakwaters for habitat enhancement on a residential scale. Environmental Management 55: 383-391.

Scyphers, Steven B., Sean P. Powers, Kenneth L. Heck Jr., and Dorothy Byron. 2011. Oyster reefs as natural breakwaters mitigate shoreline loss and facilitate fisheries. PloS One 6: e22396.

Seitz, R.D., R.N. Lipcius, N.H. Olmstead, M.S. Seebo, and D.M. Lambert. 2006. Influence of shallow-water habitats and shoreline development on abundance, biomass, and diversity of benthic prey and predators in Chesapeake Bay. Marine Ecology Progress Series 326: $11-27$.

Snelgrove, Paul V.R. 1999. Getting to the bottom of marine biodiversity: sedimentary habitats. Bioscience 49 (2): 129-138.

Sobocinski, Kathryn L., Jeffery R. Cordell, and Charles A. Simenstad. 2010. Effects of shoreline modifications on supratidal macroinvertebrate fauna on Puget Sound, Washington beaches. Estuaries and Coasts 33: 699-711.

Sturdevant, Angela, Christopher B. Craft, and John N. Sacco. 2002. Ecological functions of an impounded marsh and three natural estuarine marshes along Woodbridge River, NY/NJ Harbor. Urban Ecosystems 6: 163-181.

Swamy, Varun, Paul E. Fell, Misha Body, Michael B. Keaney, Mawuli K. Nyaku, Elizabeth C. Mcilvain, and Alice L. Keen. 2002. Macroinvertebrate and fish populations in a restored impounded salt marsh 21 years after the reestablishment of tidal flooding. Environmental Management 29: 516-530.

Swann, LaDon. 2008. The use of living shorelines to mitigate the effects of storm events on Dauphin Island, Alabama, USA. In: Mitigating impacts of natural hazards on fishery ecosystems, ed. K. D. McLaughlin, 47-57. American Fisheries Society, Bethesda MD.

Toft, Jason D., Jeffery R. Cordell, Charles A. Simenstad, and Lia A. Stamatiou. 2007. Fish distribution, abundance, and behavior along city shoreline types in Puget Sound. North American Journal of Fisheries Management 27: 465-480.
Toft, Jason D., Andrea S. Ogston, Sarah M. Heerhartz, Jeffery R. Cordell, and Emilie E. Flemer. 2013. Ecological response and physical stability of habitat enhancements along an urban armored shoreline. Ecological Engineering 57: 97-108.

Torre, Michael P., and Timothy E. Targett. 2016. Nekton assemblages along riprap-altered shorelines in Delaware Bay, USA: comparisons with adjacent beach. Marine Ecology Progress Series 548: 209-218.

Tyrell, M.C., and James E. Byers. 2007. Do artificial substrates favor nonindigenous fouling species over natives? Journal of Experimental Marine Biology and Ecology 342: 54-60.

Vaselli, Stefano, Fabio Bulleri, and Lisandro Benedetti-Cecchi. 2008. Hard coastal-defence structures as habitats for native and exotic rocky-bottom species. Marine Environmental Research 66: 395-403.

Weggel, J.R. 1988. Seawalls: the need for research, dimensional considerations and a suggested classification. Journal of Coastal Research Special Issue 4 29-39.

Weigel, Robert L. 2002a. Seawalls, seacliffs, beachrock: what beach effects? Part 1. Shore \& Beach 70: 13-22.

Weigel, Robert L. 2002b. Seawalls, seacliffs, beachrock: what beach effects? Part 2. Shore \& Beach 70: 13-22.

Weigel, Robert L. 2002c. Seawalls, seacliffs, beachrock: what beach effects? Part 3. Shore \& Beach 70: 2-14.

Windham-Myers, Lisamarie, Kristen Ward, Mark Marvin-DiPasquale, Jennifer L. Agee, Le H. Kieu, and Evangelos Kakouros. 2013. Biogeochemical implications of episodic impoundment in a restored tidal marsh of San Francisco Bay, California. Restoration Ecology 21: $124-132$

Wong, Melisa C., Charles H. Peterson, and Michael F. Piehler. 2011. Evaluating estuarine habitats using secondary production as a proxy for food web support. Marine Ecology Progress Series 440: 11-25.

Zhu, Shutang, and Allen T. Chwang. 2001. Investigations on the reflection behaviour of a slotted seawall. Coastal Engineering 43: 93-104. 